\title{
GENETIC STUDY OF MISSING C TRIRADIUS ON THE PALM: ESTIMATION OF THE HERITABILITY OF LIABILITY
}

\author{
Kazumichi Katayama \\ Department of Legal Medicine, Osaka Medical School \\ Takatsuki-City, Osaka 569, Japan
}

\begin{abstract}
Summary Palm prints of 374 parents and 362 children collected from 187 families of Japanese were studied with special reference to a missing c triradius. It was noted that the missing $\mathrm{c}$ triradius occurred with significantly increased frequency in the children of affected parents compared with that in all children studied, indicating the presence of genetic factors in its expression. It was suggested that the segregation data were more consistent with the effect of polygenic rather than monogenic inheritance in the causation of this trait. Analysis of the data by Falconer's method demonstrated that the heritability of the missing $\mathrm{c}$ triradius was calculated to be $105.0 \pm 16.3 \%$, indicating the possibility of multifactorial origin with very strong genetic determination (nearly $100 \%$ ) in the genesis of this trait.
\end{abstract}

\section{INTRODUCTION}

The digital triradius on the palm is sometimes missing. Although this characteristic seems to be genetically controlled to some degree (Kloepfer, 1977), the mode of inheritance and the degree of genetic determination have not yet been clarified satisfactorily. Especially the $\mathrm{c}$ triradius is missing in an extremely high frequency compared with the other digital triradii, i.e., on one or both palms in about one in eight individuals in the Japanese (Kasai, 1951).

The purpose of the present study is to analyze the segregation of the missing $\mathrm{c}$ triradius in 187 families, to determine whether it appears more frequently in the children born to parents with this trait than in the general population, and to assess the degree of genetic determination by the method of Falconer (1965).

\section{MATERIALS AND METHODS}

In the present study the missing $\mathrm{c}$ triradius was singled out and the abortive $\mathrm{C}$ main line was excluded for the sake of simplifying the analysis.

Received October 9, 1979 
Palm prints of 374 parents and 362 children were collected from 187 families of students and staff of Osaka Medical School, consisting of 393 males and 343 females. They were all Japanese. Sex was disregarded, since our previous study showed no sex difference in the frequency of this trait (Katayama and Toyomasu, 1979).

For each palm, the presence or absence of the $c$ triradius was formulated according to the description of Cummins and Midlo (1961), and the presence of the $\mathrm{c}$ triradius was represented by $\mathrm{c}$ and the absence by - . In the formulations, care was taken not to interpret an accessory d triradius as a $\mathrm{c}$ triradius and a rudimentary triradius ( $\mathrm{x}$ in the sense of Cummins and Midlo) as a missing triradius.

The degree of genetic determination was assessed by the method proposed by Falconer (1965).

\section{RESULTS}

The segregation of the missing $\mathrm{c}$ triradius in the parents and children is shown in Table 1, where the families are arranged in decreasing order of the number of triradii observed in the parents, i.e., the degree of affectedness.

It is obvious that the number of missing $\mathrm{c}$ triradii in the children increases with that in their parents. This indicates that there is clear correlation between parents and their children regarding the occurrence of the missing $\mathrm{c}$ triradius.

Among the 262 children of the parents neither of whom had the missing $\mathrm{c}$ triradius, $15(5.7 \%)$ presented the missing state on one or both palms, this proportion being significantly smaller than that in the total children $(14.9 \%)\left(\chi^{2}=12.92, p<\right.$ 0.001). This suggests that the missing $\mathrm{c}$ triradius is not inherited by autosomal dominant gene with nearly complete penetrance.

These data may be more consistent with the effect of polygenic rather than monogenic inheritance in the causation of the missing $c$ triradius.

Table 1. Frequency of missing $\mathrm{c}$ triradii in children from different mating types (Parental sex not distinguished).

\begin{tabular}{|c|c|c|c|c|c|c|}
\hline \multicolumn{2}{|c|}{ Mating type } & \multicolumn{5}{|c|}{ Incidence in children } \\
\hline & $\mathbf{N}$ & $\mathrm{n}$ & $\mathrm{cc}$ & $c-$ & -- & $c-$ and-- \\
\hline $\operatorname{cc} \times c c$ & 138 & 262 & $247(94.3 \%)$ & $11(4.2 \%)$ & $4(1.5 \%)$ & $5.7 \%$ \\
\hline $\operatorname{cc} \times c-$ & 28 & 59 & $40(67.8 \%)$ & $15(25.4 \%)$ & $4(6.8 \%)$ & $32.2 \%$ \\
\hline $\operatorname{cc} x-$ & 14 & 27 & $15(55.6 \%)$ & $6(22.2 \%)$ & $6(22.2 \%)$ & $44.4 \%$ \\
\hline$c-\times c-$ & 3 & 5 & $3(60.0 \%)$ & $1(20.0 \%)$ & $1(20.0 \%)$ & $40.0 \%$ \\
\hline$c-x-$ & 4 & 9 & $3(33.3 \%)$ & $4(44.4 \%)$ & $2(22.2 \%)$ & $66.6 \%$ \\
\hline$-x-$ & 0 & 0 & - & - & - & - \\
\hline Total & 187 & 362 & $308(85.1 \%)$ & $37(10.2 \%)$ & $17(4.7 \%)$ & $14.9 \%$ \\
\hline
\end{tabular}


In the method of Falconer, the degree of genetic determination in an all-or-none trait whose genetic component is multifactorial can be assessed by a value known as the heritability of liability $\left(h^{2}\right)$, which can be estimated from two observed incidences from the general population and from the first degree relatives of affected individuals.

The Falconer method is applicable to the present study under the assumption: 1) that there is an underlying variable (or liability) immediately related to the causation of the missing $\mathrm{c}$ triradius, 2 ) that such a variable is inherited by some additive genes of independent effect, and 3) that all individuals above a certain value of liability (or threshold) exhibit missing c triradii on one or both palms and all below it do not.

In this study, the incidence of the missing $\mathrm{c}$ triradius in all children was considered as that of the general population. This incidence and that among the children of parents affected on at least one palm were used to estimate the heritability of liability to the missing $\mathrm{c}$ triradius. These incidences and the significance test of the heterogeneity between both values are shown in Table 2 , in which, when both the father and mother of the same family ware affected, their children were counted twice.

The result shows that the unilaterally affected (c-), the bilaterally affected (- -), and the combined ( $c-$ and -- ) children occurred in a significantly increased frequency from the affected parents, $\mathrm{p}<0.001$ for all categories.

From $14.9 \%$ and $41.2 \%$, the incidences of the missing $\mathrm{c}$ triradius in whole children and in the children of affected parents respectively, the regression coefficient of children on parents is calculated at 0.525 by equation (2) in Falconer (1965). Whence the heritability of liability is

$$
h^{2}=2 \times 0.525=1.050 \text {, or } 105 \% \text {. }
$$

Further, the standard error of the heritability is calculated at 0.163 , or $16.3 \%$, by Method 1 of Appendex B in Falconer (1965).

Thus, the heritability of liability to the missing $c$ triradius estimated from these data is

$$
h^{2}=105.0 \pm 16.3 \%\left(88.7 \%<h^{2}<121.3 \%\right)
$$

Table 2. The incidences of the missing $\mathrm{c}$ triradius in all children and in the children of parents with at least one missing $c$ triradius.

\begin{tabular}{cccc}
\hline $\begin{array}{c}\text { Degree of } \\
\text { affectedness }\end{array}$ & $\begin{array}{c}\text { Incidence } \\
\text { in all } \\
\text { children } \\
(\%)\end{array}$ & $\begin{array}{c}\text { Incidence in the } \\
\text { children of } \\
\text { affected parents } \\
(\%)\end{array}$ & $\begin{array}{c}\text { Significance } \\
\text { of } \\
\text { difference } \\
\left(\chi^{2}\right)\end{array}$ \\
\hline c- & 10.2 & $31 / 114=27.2$ & $20.24(\mathrm{p}<0.001)$ \\
- & 4.7 & $16 / 114=14.0$ & $11.87(\mathrm{p}<0.001)$ \\
c- and -- & 14.9 & $47 / 114=41.2$ & $35.89(\mathrm{p}<0.001)$ \\
\hline
\end{tabular}

Vol, 25, No. 1, 1980 
This estimate suggests a genetic influence of between 88 and $100 \%$, and is equivalent to those of the radial border termination of the thenar crease on the palm (Tay, 1979) and Indian childhood cirrhosis (Agarwal et al., 1979). Accordingly, analysis by the Falconer method suggests a possibility that the missing $\mathrm{c}$ triradius is of multifactorial origin with very strong genetic determination (over $88 \%$ ).

\section{DISCUSSION}

The method of assessing the degree of genetic determination proposed by Falconer (1965) is based on the correlation between relatives as mentioned above. It could, of course, be argued that the increase in frequency of a given trait in the relatives of affected individuals may also be due to common environmental factors operating in these relatives. With regard to various dermatoglyphic traits, however, it is now well established that the final dermatoglyphic pattern is set before the sixth month of gestation and is not changed in the post-natal period (Holt, 1968). Therefore, any common environmental factors operating in the relatives must be intrauterine. Thus, if there is an increased frequency of a dermatoglyphic trait in the children or parents rather than in the sibs of affected individuals, few common intrauterine factors can be involved. In other words, it can be concluded that the increase in frequency of the missing $\mathrm{c}$ triradius in the children of affected individuals is exclusively due to genetic factors.

As the simplest model, Kloepfer (1977) and Kloepfer and Parisi (1978) have proposed the mode of inheritance of this trait by an autosomal dominant gene with incomplete penetrance. Since the concept "penetrance" seems ambiguous from a genetic point of view, however, the penetrance value under the monogenic hypothesis may be less appropriate for assessing the degree of genetic determination than the heritability value under the polygenic hypothesis, especially in the case of dermatoglyphic traits. There is general agreement that most dermatoglyphic traits are inherited by a polygenic system, with some genes contributing a small additive effect (Schaumann and Alter, 1976).

Additionally it should be noted that the missing c triradius is found with increased frequency in various congenital anomalies such as chromosomal aberrations and genetic or sporadic disorders, as reviewed by Schaumann and Alter (1976). These facts are not to be well interpreted by a single gene concerning with the genesis of this trait.

\section{REFERENCES}

Agarwal, S.S., Lahori, U.C., Mehta, S.K., Smith, D.G., and Bajpai, P.C. 1979. Inheritance of Indian childhood cirrhosis. Hum. Hered. 29: 82-89.

Cummins, H., and Midlo, C. 1961. Finger Prints, Palms and Soles. Dover, New York, pp. 84-119. Falconer, D.S. 1965. The inheritance of liability to certain diseases, estimated from the incidence among relatives. Ann. Hum. Genet. 29: 51-76.

Jpn. J. Human Genet. 
Holt, S.B. 1968. The Genetics of Dermal Ridges. Charles C. Thomas, Springfield, Illinois, pp. 5-11. Kasai, K. 1951. Frequency of main line in Japanese, classified by Wilder's and its revised method by Cummins-Midlo. Jap. J. Legal Med. 5: 147-154 (in Japanese).

Katayama, K. and Toyomasu, T. 1979. The incidences and parent-child correlations of irregular types in digital triradii a, b, c, and d. J. Anthrop. Soc. Nippon 87: 166 (in Japanese).

Kloepfer, H.W. 1977. A genetic model for the inheritance of a dermatoglyphic trait: Absence of the palmar c-triradius. In: Dermatoglyphics. An International Perspective (J. Mavalwala ed.). World Anthropology Series, Mouton, The Hague: 223-230.

Kloepfer, H.W., and Parisi, P. 1978. Penetrance of gene for absence c-triradius from 567 sets of monozygotic twins. Prog. Clin. Biol. Res. 24 (part C): 269-275.

Schaumann, B., and Alter, M. 1976. Dermatoglyphics in Medical Disorders. Springer-Verlag, New York, pp. 131-252.

Tay, J.S.H. 1979. The genetics of palmar creases, a study in the inheritance of liability estimated from the incidence among relatives. Ann. Hum. Genet. 42; 327-332. 